\title{
Health and educational outcomes of children who experienced severe neonatal medical complications
}

Timothy B. Smith

Brigham Young University, tbs@byu.edu

Glenna C. Boyce

Utah State University

Glendon Castro

University of Utah, SJ Quinney College of Law

Follow this and additional works at: https://scholarsarchive.byu.edu/facpub

Part of the Medicine and Health Sciences Commons

\section{BYU ScholarsArchive Citation}

Smith, Timothy B.; Boyce, Glenna C.; and Castro, Glendon, "Health and educational outcomes of children who experienced severe neonatal medical complications" (1999). Faculty Publications. 3148.

https://scholarsarchive.byu.edu/facpub/3148

This Peer-Reviewed Article is brought to you for free and open access by BYU ScholarsArchive. It has been accepted for inclusion in Faculty Publications by an authorized administrator of BYU ScholarsArchive. For more information, please contact ellen_amatangelo@byu.edu. 
Running head: HEALTH AND EDUCATIONAL OUTCOMES

\author{
Health and Educational Outcomes of Children Who Experienced \\ Severe Neonatal Medical Complications \\ Glenna C. Boyce, Timothy B. Smith, and Glendon Casto \\ Early Intervention Research Institute ${ }^{1}$ \\ Utah State University
}

${ }^{1}$ Work reported in this manuscript was supported in part with funds from the U.S. Department of Education (Contract \#HS90010001) to the Early Intervention Research Institute at Utah State University. 


\begin{abstract}
To determine the long-term developmental and educational outcomes of a sample of low birthweight infants with intraventricular hemorrhage (IVH), developmental assessments and interviews were conducted eight years after the initiation of an early intervention project. At the time of the follow-up, $62 \%$ of children were experiencing some developmental or behavior problems, with visual impairments, cerebral palsy, and attention deficits occurring most frequently. Grade of IVH and the number of days spent in the neonatal intensive care unit were the best predictors of later developmental delays. The sample also scored below average on school achievement; approximately $30 \%$ of those in school were eligible for special education services. These findings corroborate results from investigations with similar populations, whose birth characteristics put them at-risk for subsequent developmental delay.
\end{abstract}




\section{Health and Educational Outcomes of Children Who Experienced}

Severe Neonatal Medical Complications

One of the primary contributors to infant mortality is low birthweight (LBW). In the USA, $6.8 \%$ of all newborn babies are LBW (weighing $2500 \mathrm{~g}$ or less at birth), and about $1.2 \%$ are very low birthweight (weighing $1500 \mathrm{~g}$ or less at birth). Approximately 20 to $40 \%$ of LBW infants (or approximately 90,000 infants per year) suffer periventricular-intraventricular hemorrhages (IVH) within 72 hours of birth (Volpe, 1981; Wildrick, 1997). These hemorrhages produce abnormal bleeding from cranial capillaries that result in different degrees of neurological damage based upon the severity of the hemorrhage. Brain-imaging procedures such as realtime ultrasonogram and computed tomography scanning are used to make a positive identification of IVH and to classify the hemorrhage into one of four grades of severity, with Grade I the most mild form of hemorrhage and Grade IV the most severe (Papile, Burstein, Burstein, \& Koffler, 1978). Dramatic clinical symptoms such as seizures, loss of muscle tonus, cessation of breathing, and unreactive pupils, may mark the onset of IVH; however, at times IVH is clinically silent. The importance of IVH as a major health problem is underscored by the fact that for each 1,000 LBW infants born: (a) 400 suffer IVH; (b) 100 of the 400 (25\%) die immediately; and (c) 85 of the remaining $300(28 \%)$ suffer major neuropsychological impairment (Volpe, 1987).

Information as to the longitudinal developmental progress of IVH survivors is limited and controversial (Bendersky \& Lewis, 1995; Whitehead, 1993). For example, Sostek, Smith, Katz, and Grant (1987) concluded that the severity of IVH did not predict the infant's developmental progress at 2 years of age; however, $40 \%$ of the infants in that study showed significant delays at 2 years. 
The problem with most follow-up studies is that their investigations have typically been limited to two or three years, and calls for additional, long-term longitudinal studies have appeared with frequency in the literature (i.e., Hack, Klien, \& Taylor, 1995). Since few studies have investigated prospectively the health, developmental, and educational outcomes of medically fragile infants when they reach school-age, the present study was conducted to increase our understanding of these variables and to identify potential longitudinal predictors of developmental outcomes.

Method

\section{Sample}

In the present study, 58 families with children (47\% male) who experienced IVH were recruited across a three year period (1987-1989) from the neonatal intensive care units (NICUs) of two hospitals in Salt Lake City, Utah (see Boyce, Smith, Immel, Casto, \& Escobar, 1993). All of the children but one were premature (mean gestational age was 30.0 weeks); and all but two had low or very low birthweights (mean birthweight was $1407.7 \mathrm{~g}$ ). The mean age of the children at the time of the survey conducted for this project was 7.0 years, with ages ranging from 5 to 8.5 .

\section{$\underline{\text { Procedure }}$}

Several years after initial recruitment, fifty-five (95\%) of the families participated in a structured outcome interview (one family could not be located and two of the children had died). Most of the respondents were mothers (87\%), but six fathers and one grandparent (the primary caregiver) also participated. Caregivers were asked whether medical or school personnel had diagnosed the child with the conditions listed in Table 1 and whether they thought the child did indeed have the condition. Answers were coded as yes, no, or uncertain (i.e., diagnosis presently is unsure and warrants further evaluation). Specific educational information collected 
included present school placement, grade completion/repetition, and strategies they had used to prepare their child for school. (A copy of the interview may be obtained from the first author).

Insert Table 1 about here

The short form of the Woodcock-Johnson Tests of Achievement--Revised (WJR; Woodcock \& Johnson, 1989), a widely used norm-referenced test, was individually administered to children who had reached the age of 78 months to assess their school achievement. The WJ-R provides two summary scores (i.e., broad knowledge and skills knowledge) which are based on six aspects of scholastic achievement: letter-word identification, applied problems, dictation, science, social studies, and humanities. The general development or independent functioning of the child was assessed with the Scales of Independent Behavior (SIB; Bruininks, Woodcock, Weatherman, \& Hill, 1984), a norm referenced test based on parent reports of child behaviors in four areas: motor skills, social and communication skills, personal living skills, and community living skills. For the children who were in kindergarten or later grades, school teachers completed two mailed questionnaires. On the first of these, the teacher provided a description of the child's present educational program (i.e., type of classroom, services received, and eligibility for special education services, etc.). On the second, the Social Skills Rating System (SSRS; Gresham \& Elliott, 1990), the teacher rated the child's social behaviors affecting teacher-student relations, peer acceptance, and academic performance. Two scores are derived: the child's social skills (including control, assertion, and self-control) and problem behaviors (externalizing, internalizing, and hyperactivity), with higher scores indicative of greater behavior frequency. 
Several statistical strategies were employed to analyze the findings. First, descriptive statistics were used to characterize the sample and results of the survey. The conditions investigated included cerebral palsy, intellectual disabilities, attention problems, vision problems, eligibility for special education, and no present diagnosis (i.e., healthy). Crosstabulations were used to compare the distribution of IVH in the total sample with the distribution of IVH for each condition. I-tests to compare those children with and without a condition were completed for each condition to investigate the effect of birthweight, gestational age, and days in intensive care. Correlations were used to assess which birth data variables were most predictive of later developmental status.

\section{Results and Discussion}

\section{$\underline{\text { Health/Developmental Conditions }}$}

Overall, there appeared to be large differences in the present level of health and behavioral outcomes within this group of children. Thirty-eight percent of the children did not have any of the conditions specified in the interview. Among the other children, a variety of health- and behavior-related problems were reported. As can be seen in Table 1, visual impairments were the most frequently reported problem. Second in frequency were problems with either fine or gross motor functioning. Nine of the children (16\%) had been diagnosed as having cerebral palsy. The fact that motor problems occurred so frequently is consistent with research conducted with similar samples (Bendersky \& Lewis, 1995; Bozynski et al., 1984; Msall, Buck, Rogers, \& Cantanzaro, 1992; Sostek, 1992). Hearing, intellectual, and communication problems were less common ( $9 \%, 9 \%$, and $16 \%$, respectively).

The incidence of attention problems, although not yet well established, appears to be high. Over one-fourth of the children may suffer from the inability to attend (i.e., attention deficit 
hyperactivity disorder [ADD or ADHD]). The national average for children with attention problems is approximately five percent.

Three children were experiencing seizures and one had a heart condition. These conditions had been experienced by more of the children when they were younger, but either they were no longer having problems or the parents had been advised that the condition was no longer a concern.

Among the $62 \%$ for whom one or more conditions were reported, eleven children ( $20 \%$ of the total sample) accounted for the majority of the problems reported, with each of them having at least four medical conditions. In a similar longitudinal study of premature infants, $63 \%$ had one or more minor impairments, while $22 \%$ had major neurodevelopmental impairments (Msall et al., 1992).

\section{Neonatal Predictors of Childhood Development}

To investigate the relationships between present disabilities and neonatal characteristics, group mean comparisons were conducted. Groups with particular conditions (e.g., cerebral palsy, intellectual disability, attention problems) as well as those children who presently have no present diagnosis were examined as to grade of IVH, birth weight, gestational age, and days in intensive care. Table 2 presents these findings.

Insert Table 2 about here

The distribution of IVH levels in the groups that currently have cerebral palsy, intellectual disabilities, special education eligibility was significantly different from the distribution of IVH levels in the total sample. A higher proportion of children with Grade IV IVH were in the cerebral palsy, intellectual disabilities, and special education eligibility groups than in the total 
sample. Oppositely, none of the healthy children had experienced grade IV IVH. Birthweight and number of days spent in intensive care also appeared to be related to some (e.g., cerebral palsy), but not all, of the health conditions. Notably, healthy children were those who had spent the fewest days in the NICU as neonates, regardless of their birthweight or gestational age.

To further investigate the relationship between neonatal characteristics and later developmental outcomes, correlations were computed using the Battelle Develpomental Inventory (Newborg, Stock, Wnek, Guidubaldi, \& Svinicki, 1984) as a standardized measure of developmental status $(\underline{M}=100, \underline{S D}=15)$. As may be seen in Table 3, birthweight and gestational age at birth were not consistently related to later developmental outcomes. However, grade of IVH and, particularly, the number of days spent in the NICU were statistically significantly related to later functioning. Future research would do well to investigate the predictive utility of these variables.

Insert Table 3 about here

\section{Educational Outcomes}

At the time of the survey all but seven of the 55 children were in public school (kindergarten, first or second grades). One child's schooling was provided by a home teacher due to the severity of her health conditions and disabilities. Table 4 provides details concerning educational outcomes. Of the children in school, almost one-third were eligible for special education services. Almost $80 \%$ were attending regular classrooms, but approximately $15 \%$ of the children received additional services, such as therapy or resource services. Only $19 \%$ were in self-contained special education classrooms. 
Insert Table 4 about here

School achievement (measured by the WJ-R) appeared to be somewhat low when compared to the WJ-R standardized norms $(\underline{\mathrm{M}}=100, \underline{\mathrm{SD}}=15)$. The standard deviations indicate a wide range of scores. As a group, the children's broad knowledge scores $(\underline{M}=93.8)$ were significantly higher than the skills knowledge scores $(\underline{M}=83.3 ; \underline{p}<.001)$. Almost onefourth of the children scored one standard deviation $(\leq 85)$ below the mean on the broad knowledge scale, while almost one-half scored 85 or below on the skills knowledge. Skills knowledge includes letter-word identification, applied problems and dictation. Because these tasks call for motor dexterity, the skills knowledge score may have been more affected by the motor problems that some of the children have than the broad knowledge score.

General development, as measured by the total SIB score, was also somewhat delayed for this group; $26 \%$ of the children scored greater than one standard deviation below the mean $(\leq$ 85). Motor skills and community living skills (which a child needs to function effectively in the community) were particularly low.

These educational outcomes support findings of other studies of children who, due to neonatal characteristics, were also developmentally at risk. For example, one investigation of 33 five to eight year olds whose birth weights had been less than $1250 \mathrm{~g}$ found that although $90 \%$ were in regular classrooms, almost half of them received remedial instruction (Eilers, Desai, Wilson, \& Cunningham, 1986). In a similar study of 101 eight year olds whose birthweights were less than or equal to $1500 \mathrm{~g}$, over $30 \%$ had received special education services and/or grade repetition (Hunt, Tooley, \& Cooper, 1992).

Social development is an important aspect of school participation. A great variability is seen in this group in social skills and problem behaviors. The vast majority did fall within the 
normal range, but $28 \%$ scored one standard deviation below the mean (85 or less) on the measure of social skills (SSRS), indicating lower social skills. In addition, 25\% percent had high problem behavior scores (>115).

In summary, the majority of the children followed in this longitudinal study had some health and/or behavior-related problems, and $20 \%$ presented very serious neurodevelopmental impairments. As a group, they had a higher than expected incidence of visual, motor (including cerebral palsy), and attention problems. Their overall educational achievement levels were also below expected levels. Importantly, the number of days spent in the NICU as well as the severity of IVH were predictive of developmental status five to eight years after birth. Taken together, these data suggest that neonates with grade IV IVH and prolonged hospitalizations (and not necessarily those with low birthweight or prematurity) are notably at risk by the time they enter the public school system. Further follow-up will determine if these children continue to be at risk or if their experiences in the school system reduce their initial deficits over time. 


\section{References}

Bendersky, M., \& Lewis, M. (1995). Effects of intraventricular hemorrhage and other medical and environmental risks on multiple outcomes at age three years. Journal of Developmental and Behavioral Pediatrics, 16(2), 89-96.

Boyce, G. B., Smith, T. B., Immel, N., Casto, G., \& Escobar, C. (1993). Early intervention with Medically Fragile Infants: Investigating the Age-At-Start Question. Early Education and Development, 4, 290-305

Bozynski, M. E., Nelson, M. N., Rosati-Skertick, C., Genaze, D., O'Donnell, K., \& Naughton, P. (1984). Two year longitudinal follow-up of premature infants weighing $\leq 1,200$ grams at birth: Sequelae of intracranial hemorrhage. Developmental and Behavioral Pediatrics, $\underline{5}, 346-352$.

Bruininks, R. K., Woodcock, R. W., Weatherman, R. F., \& Hill, B. K. (1984). Scales of Independent Behavior. Itasca, IL: Riverside.

Eilers, B. C., Desai, N. S., Wilson, M. A., \& Cunningham, M. D. (1986). Classroom performance and social factor's of children with birthweights of 1,250 grams or less: Follow-up at 5 to 8 years of age. Pediatrics, $77,203-208$.

Gresham, F. M., \& Elliott, S. N. (1990). Social skills rating system manual. Circle Pines, MN: American Guidance Service.

Hack, M., Klien, N. K., \& Taylor, H. G. (1995). Long-term developmental outcomes of low birth weight infants. The Future of Children, 5(1), 176-192.

Hunt, J. V., Tooley, W. H., \& Cooper, B. A. B. (1992). Further investigations of intellectual status at age 8 years: I Long term consequences into adulthood, II Neonatal predictors. In S. L. Friedman \& M. D. Sigman (Eds.), The psychological Development of Low Birthweight Children, (pp. 315-337). Norwood, NJ: Alex Publishing Corporation. 
Msall, M. E., Buck, G. M., Rogers, B. T., Cantanzaro, N. L. (1992). Kindergarten readiness after extreme prematurity. American Journal of Diseases of Children, 146, 13711375.

Newborg, J., Stock, J., Wnek, L., Guidubaldi, J., \& Svinicki, J. (1984). Battelle developmental inventory. Allen, TX: DLM Teaching Resources.

Papile, L. A., Burstein, J., Burstein, R., \& Koffler, H. (1978). Incidence and evolution of subependymal and intraventricular hemorrhage: A study of infants with birth weights less than $1500 \mathrm{gm}$. The Journal of Pediatrics, 92, 529-534.

Sostek, A. M. (1992). Prematurity as well as IVH: Influence on developmental outcomes at five years. In S. L. Friedman \& M. D. Sigman (Eds.), The Psychological Development of Low Birthweight Children, (pp. 359-274). Norwood, NJ: Alex Publishing Corporation.

Sostek, A., Smith, Y., Katz, K., \& Grant. E. (1987). Developmental outcome of preterm infants with intraventricular hemorrhage at one and two years of age. Child Development, 58, 779-786.

Volpe, J. J. (1981). Neonatal intraventricular hemorrhage. The New England Journal of Medicine, 304, 886-891.

Volpe, J. J. (1987). Neurology of the newborn. Philadelphia, PA: Saunders, Co.

Whitehead, A. J. (1993). Developmental outcome of very low birth weight infants with intraventricular hemorrhage. Perceptual and Motor Skills, 77, 894.

Wildrick, D. (1997). Intraventricular hemorrhage and long-term outcome in the premature infant. Journal of Neuroscience Nursing, 29, 281-290.

Woodcock, Z. W., \& Johnson, M. B. (1989). Woodcock-Johnson Psychoeducational Battery-Revised. Allen, TX: DLM Teaching Resources. 
Table 1

Survey of Health/Behavioral Conditions, in Percentages

\begin{tabular}{|c|c|c|c|c|c|c|}
\hline \multirow[b]{2}{*}{ Condition } & \multicolumn{3}{|c|}{ Professional Opinion } & \multicolumn{3}{|c|}{ Parent Opinion } \\
\hline & No & Yes & Uncertain & No & Yes & Uncertain \\
\hline Vision Problems & 71 & 25 & 4 & 71 & 25 & 4 \\
\hline Hearing Problems & 91 & 9 & 0 & 89 & 7 & 4 \\
\hline Communication Problems & 84 & 16 & 0 & 86 & 14 & 0 \\
\hline Visual/Motor Problems & 76 & 22 & 2 & 74 & 24 & 2 \\
\hline Orthopedic Problems & 80 & 20 & 0 & 78 & 22 & 0 \\
\hline Attention Problems & 76 & 18 & 6 & 69 & 25 & 6 \\
\hline Behavioral Problems & 89 & 6 & 5 & 87 & 7 & 6 \\
\hline Learning Problems & 89 & 4 & 7 & 85 & 6 & 9 \\
\hline Intellectual Disability & 89 & 9 & 2 & 89 & 7 & 4 \\
\hline Seizures & 93 & 6 & 2 & 93 & 5 & 2 \\
\hline Cerebral Palsy & 84 & 16 & 0 & 84 & 16 & 0 \\
\hline Heart Condition & 93 & 2 & 5 & 94 & 2 & 4 \\
\hline
\end{tabular}


Table 2

Neonatal Risk Factors Among Children with Specific Developmental Conditions

\begin{tabular}{|c|c|c|c|c|c|c|c|}
\hline $\begin{array}{l}\text { Condition/ } \\
\text { Birth Data } \\
\end{array}$ & $\begin{array}{l}\text { Total } \\
\text { Sample } \\
(\underline{n}=55)\end{array}$ & $\begin{array}{l}\text { Cerebral } \\
\text { Palsy } \\
(\underline{n}=9) \\
\end{array}$ & $\begin{array}{l}\text { Intellectually } \\
\text { Disabled } \\
(\underline{\mathrm{n}}=6)\end{array}$ & $\begin{array}{l}\text { Attention } \\
\text { Problems } \\
(\underline{n}=13)\end{array}$ & $\begin{array}{l}\text { Vision } \\
\text { Problems } \\
(\underline{n}=16)\end{array}$ & $\begin{array}{l}\text { Eligible for } \\
\text { Special } \\
\text { Education }^{a} \\
(\underline{n}=15)\end{array}$ & $\begin{array}{l}\text { No Present } \\
\text { Diagnosis }^{\mathrm{b}} \\
(\underline{\mathrm{n}}=21)\end{array}$ \\
\hline \multicolumn{8}{|l|}{$\begin{array}{c}\text { Group Percentages } \\
\text { Grade of IVH }\end{array}$} \\
\hline I & 34.5 & $22.2^{+}$ & $33.3^{+}$ & 38.5 & 31.3 & $26.7^{+}$ & $38^{+}$ \\
\hline II & 30.9 & 11.1 & 0 & 38.5 & 18.7 & 13.3 & 48 \\
\hline III & 20.0 & 22.2 & 16.7 & 15.4 & 31.3 & 26.7 & 14 \\
\hline IV & 14.5 & 44.4 & 50.0 & 7.7 & 18.7 & 33.3 & 0 \\
\hline \multicolumn{8}{|l|}{ Group Means } \\
\hline Birthweight (in grams) & 1407.7 & $1162.2^{*}$ & 1180.0 & 1473.5 & 1447.8 & $1220.0^{*}$ & 1413.1 \\
\hline Gestational Age (in weeks) & 30.0 & 28.4 & 28.7 & 30.5 & 30.8 & 29.5 & 29.9 \\
\hline Days in NICU & 30.6 & 27.7 & $61.8^{*}$ & 33.0 & 41.3 & 44.1 & $19.7^{*}$ \\
\hline
\end{tabular}

${ }^{a} E$ Eligibility for special education was reported via teacher questionnaire.

${ }^{\mathrm{b}}$ These children experienced none of the conditions assessed.

${ }^{+}$Distribution for these conditions were statistically significantly different, chi square, alpha $\leq .05$.

${ }^{*} \underline{\mathrm{p}} \leq .05$. 
Table 3.

Health and Educational Outcomes

Bivariate Correlations of Battelle Developmental Inventory Scores and Birth Data

\begin{tabular}{lcccccc}
\hline Birth Data & $\begin{array}{l}\text { Personal/ } \\
\text { Social }\end{array}$ & $\begin{array}{l}\text { Adaptive } \\
\text { Behavior }\end{array}$ & Motor & Communication & Cognitive & TOTAL \\
\hline Grade of IVH & -.19 & $-.28^{*}$ & $-.48^{* *}$ & -.22 & $-.34^{*}$ & $-.33^{*}$ \\
Birthweight & .19 & .22 & .25 & .18 & .19 & .20 \\
Gestational age & .24 & .27 & .26 & .19 & .19 & .24 \\
Days in NICU & $-.43^{* *}$ & $-.41^{* *}$ & $-.43^{* *}$ & $-.46^{* *}$ & $-.55^{\star * *}$ & $-.47^{\star *}$ \\
\hline
\end{tabular}

${ }^{*} \underline{p} \leq 0.05 ; \quad{ }^{* *} \underline{p} \leq 0.01 ; \quad{ }^{* * *} \underline{p} \leq 0.001$ 
Table 4

Present Educational Information

$\% \quad \underline{M} \quad \underline{S D}$

Eligible for Special Education Services

Yes

No

\section{Educational Placement}

Regular Classroom

Regular Classroom with Therapy

Regular Classroom with Resource

Self-Contained Classroom

Home Teacher $^{\mathrm{a}}$
64.6

31.3

68.7

4.2

10.4

18.8

2.2

Woodcock Johnson Achievement-Revised (Standard Scores)

Broad Knowledge

93.8

23.4

Skills Knowledge

Scales of Independent Behavior (Standard Scores)

Motor Skills

89.1

26.4

Social \& Communication

94.4

21.6

Personal Living

95.2

23.2

Community Living

86.3

26.5

Broad Independence (Total Score)

91.2

25.2

Social Skills Rating System - Teacher Form (Standard Scores)

Social Skills

94.1

14.8

Problem Behaviors

102.6

18.0

${ }^{a}$ Severity of disabilities prevents school attendance. 